\title{
Technology and Mastery: Exploring Design Sensitivities for Technology in Mountaineering
}

\section{Keith Cheverst}

School of Computing and Communications

Lancaster University, Lancaster, U.K.

cheverst@lancaster.ac.uk

\section{Mads Bødker}

Dept. of Digitalization

Copenhagen Business Schoo

Howitzvej 60, 5.17

Copenhagen, Denmark

mb.digi@cbs.dk

\section{Florian Daiber}

DFKI, Computer Science Campus

Saarland

Saarbrücken, Germany

Florian.daiber@dfki.de

\begin{abstract}
The idea of man's 'mastery over nature' is ubiquitous in western philosophy and in western thinking and technology has been widely used in support of this end. Given the growing interaction design opportunities for personal digital technologies in supporting outdoor and recreational nature activities such as mountaineering it is timely to unpack the role that technology can play in such activities. In doing so it is important to consider the intrinsic and extrinsic motivations at play for the individual and the accepted social norms or 'rules' that are associated with the activity through its community and passed on through its community of practice. Technologies that may be considered as a form of 'cheating' when first introduced (such as handheld GPS) can later become accepted through common practice, although the rules are often nuanced. For example, it is widely regarded that GPS should not replace the skill of map reading and navigation. In this position paper we consider different forms of mastery over nature that technology can support and reflect on the design sensitivities that these provide.
\end{abstract}

\section{Author Keywords}

User experience; Design Sensitivity; Outdoor, Nature settings, Climbing, Mountaineering, Interaction design.

ACM Classification Keywords

H.5.m. Information interfaces and presentation (e.g., $\mathrm{HCI}$ ): Miscellaneous; 


\section{Introduction}

The idea of man's 'mastery over nature' is ubiquitous in western philosophy and in western thinking. As a particular term it can be attributed to Frances Bacon's Novum Organum, but it can be traced back to key passages in the old testament. Here, man (!) is told to

"fill the earth and subdue it; and have dominion over the fish of the sea and over the birds of the air and over every living thing that moves upon the earth." (Genesis, 1:28)

In considering the relationship between human, technology and nature/world, Don Ihde inquires upon:

"The isolation of a difference between technologically mediated and non-technological experiences of the world..." with the observation that "...such a difference almost always gets crossed with either a romantic or an anti-romantic interpretation in most examinations of technology via- à-vis human life. " [5]

This paper aims to analyze how 'mastery over nature' is a dominant leitmotif [4] that can be seen to motivate and shape the development of digital technologies. In considering issues around technology use in nature it is helpful to consider the reflections articulated by [1] on $2^{\text {nd }} 3^{\text {rd }}$ wave $\mathrm{HCI}$ :

"The second and the third wave seem to be stuck on either side of the divide between work on the one hand and leisure, arts, and home on the other; between rationality on the one hand and emotion on the other While development on either side may lead toward a true third wave, I don't believe that we will get there until we embrace people's whole lives and transcend the dichotomies between work, rationality, etc. and their negations."

While everyday uses of digital technology certainly involves the consumption of natural resources (power) we use examples of 'technology in nature' to emphasize how the image of "man over nature" plays out when considering the particular recreational nature activity of mountaineering/climbing. This activity is chosen because of its rich set of values and associated motivations and for the fact that popular discourse relating to the activity includes language such as 'conquer' - clearly resonating with the image of man's 'conquering nature' which originated from Frances Bacon [11].

As part of this study we consider how such understanding can play a generative role in design by deriving a set of design sensitivities. As noted by [2]:

"Design sensitivities do not impose predetermined solutions, but rather define spaces for discussion on how the design of interaction could deal with the issues that they express".

In [6] the authors describe their design work involving interactive sport-training games and argue that design sensitivities can

"emphasize issues, challenges and opportunities, important for the design, development and analysis".

In the following sections we describe our study focus climbing and mountaineering before proceeding to derive and present two design sensitivities. The paper concludes with a summary and areas for future work.

\section{Study Focus: Climbing and Mountaineering}

In this section we consider the outdoor/nature activity of climbing and mountaineering to unpack and consider more concretely the relationship (and associated issues) between new technology and 'mastery over nature'. The research literature includes examples of potential advanced technologies that can support the activity of climbing. For example, early work by [12] presents design ideas based around Location Based Services to support climbing activities. A feasibility study of the ClimbSense system is presented in [7] 
which utilises wearable sensors to automatically detect climbed routes while [10] investigates the role of emotions in learning climbing.

In understanding the potential role and adoption of technologies for climbing it is important to consider the different personal motivations at play. In [3] the authors unpack motivation into two broad types, namely: intrinsic and extrinsic and both types are present in mountaineering [8]. In more detail, one example of an intrinsic motivations could be the sense of personal satisfaction from skill mastery leading to the accomplishment of a personally challenging ascent. Conversely, one example of extrinsic motivation could be the peer recognition that a climber may seek from achieving a notable first ascent or speed record for a particular climb.

Early work considering the community aspects of climbing in relation to interaction design is presented in [13]. In this research the authors describe their study of a university climbing club as a climbing community and consider how technology might be used to support the production and maintenance of this community with particular reference to the three aspects of: Boundaries, Relationships and Change.

In considering the role that technology (in a broad sense) can play in these motivations and the dynamic nature of technology acceptance in

mountaineering/climbing it is helpful to consider the socalled 'rules' associated with the activity (and subactivities). In his seminal article entitled "Games Climbers Play" [14] Lito notes how:

"...the rules of various climbing-games are determined by the climbing community at large, but less so by climbers approaching the two extremes of ability. One of these elements is composed of those fainthearted types who desire to overcome every new difficulty with some kind of technological means rather than at the expense of personal effort under pressure, The other group is the small nucleus of elite climbers whose basic concern is not with merely ethical climbing but with minimising the role of technology and increasing that of individual effort in order to do climbs with better style." Lito also points to the interplay of adhering to rules and value, i.e. What might be considered 'good' practice.

"It is important to realise at the outset that these rules are negatively expressed although their aim is positive. They are nothing more than a series of 'dont's' : don't use fixed ropes, belays, pitons, a series of camps, etc. The purpose of these rules is essentially protective or conservative. That is, they are designed to conserve the climber's feeling of personal (moral)

accomplishment against the meaninglessness of a success which represents merely technological victory"

The rules are, however, dynamic in nature and so a technology that is deemed 'cheating' when first introduced may later be considered acceptable and compatible with a 'good' style of ascent. One example of such a technology that was initially regarded as 'bad form' was so-called 'Sticky rubber' that provided climbing shoes with superior friction on the rock and could therefore be considered as reducing the challenge or the technical skill required to ascend a given climb.

\section{Design Sensitivity 1: technical skill}

The notion of technical skill appears a key factor in the values associated with a 'good' style of ascent and consequently it is technologies that can be perceived as reducing the level of technical skill required that are likely to receive criticism. Indeed, the use of climbing chalk (see figure 1) can be seen as another example of a technology that was deemed to by many in the community (and especially those belonging to the socalled 'Clean Hand Gang') as cheating when it was first introduced because it effectively increased a climber's friction with the rock and therefore was seen as reducing the technical skill required for a given ascent. Such criticism from peers would be particularly damaging to those with a high extrinsic motivation for climbing (given peer recognition is typically regarded as an extrinsic reward). 
In terms of digital technologies, the introduction of handheld GPS units was initially regarded with

scepticism but rather than 'cheating' as such the main concern was that the positioning service would lead to a reduction in the technical skills associated with map reading and navigation and in-turn lead to an over reliance on the technology and the potential for accidents related to getting lost in the mountains.

Recognising the strong value placed on technical skill within mountaineering/climbing can be used to help generate design ideas that are more likely to receive acceptance and to recognise design ideas that are likely to cause adoption issues if introduced.

Consider, for example, the role that technologies based on personal drones or UAVs, may have in the mountains. Mayer et al. [9] describe a number of scenarios whereby personal drones could support backcountry activities. One of these scenarios is photo and video taking and in terms of not reducing technical skill required for ascent this would be unlikely to pose an adoption issue. However, the noise generated by its use in a wilderness area could certainly cause vexation to other climbers operating within listening range.

Another drone scenario that (apart from the noise) would not reduce technical skill would be one that supported the collection and appropriate disposal of detritus after a mountain ascent, e.g. collecting water/oxygen bottles, climbing gear left behind, etc.

Again such a system would not, in itself, have an impact on technical skill. However, consider a drone system developed to carry climbing gear for the climber in order to reduce the weight of his or her load. One would anticipate that such a system would (initially at least) receive criticism from the climbing community.

Consequently, the derived design sensitivity is: caution should be used when designing and introducing

technologies that may be perceived as reducing the human skill required to achieve a particular climbing ascent as such ascents are likely (at least initially) to receive peer criticism.

Design Sensitivity2: peer recognition

As noted earlier an extrinsic motivation associated with climbing is that of peer recognition. Such recognition is particularly important for the professional climber or mountaineer where the extrinsic reward can be new or continued financial sponsorship deals from established equipment manufacturers. Unfortunately situations have arisen where claimed ascents have been questioned by the climbing community and several recent news articles have pointed to the use of GPS traces in order to 'prove' summit claims (for example: https://af.reuters.com/article/worldNews/idAFKBN16R177).

Returning to the drone scenario involving the capture of video, such an approach could be used to record the style of an ascent and this video could then be shared with the climbing community in order to facilitate peer recognition and associated extrinsic rewards. Note that this acknowledgement of peer recognition resonates strongly with the extended Technology Acceptance model [15] which includes social influence as a key factor influencing technology adoption.

Consequently, the $2^{\text {nd }}$ derived design sensitivity is: technologies that may capture proof on an ascent and the style of an ascent may be adopted in order to facilitate peer recognition and defend a climber against peer scepticism relating to a claimed ascent.

\section{Summary}

In this paper we have reflected upon the image of 'man mastering nature' as a perspective for considering the design of technology in nature. Focusing on the activity of mountaineering we derived two design sensitivities that may function as an inspiration for the design of new digital technologies. 


\section{References}

1. Susanne Bødker. 2006. When second wave HCI meets third wave challenges. In Proceedings of the 4th Nordic conference on Human-computer interaction: changing roles (NordiCHI '06), Anders Mørch, Konrad Morgan, Tone Bratteteig, Gautam Ghosh, and Dag Svanaes (Eds.). ACM, New York, NY, USA, 1-8.

2. Lui Ciolfi. 2004. Situating 'Place' in Interaction Design: Enhancing the User Experience in Interactive Environments. 2004. Dept. of Computer Science and Information Systems, University of Limerick, Ireland.

3. Mihaly Csikszentmihalyi, M., \& K. Rathunde. 1993. The measurement of flow in everyday life: Toward a theory of emergent motivation. In J. E. Jacobs (Ed.), Developmental perspectives on motivation (pp. 57-97). Lincoln: University of Nebraska Press.

4. Lee Hallnäs, and Johan Redström, J. 2002. From Use to Presence: On the Expressions and Aesthetics of Everyday Computational Things. ACM Transactions on Computer-Human Interaction (TOCHI) TOCHI Homepage archive, Volume 9 Issue 2, June 2002 pp. 106-124.

5. Don Ihde. 1990. Technology and the Life World From Garden to earth. Indiana University Press. 1990.

6. Mads Møller Jensen, Majken Kirkegaard Rasmussen, and Kaj Grønbæk. 2014. Design sensitivities for interactive sport-training games. In Proceedings of the 2014 conference on Designing interactive systems (DIS '14). ACM, New York, NY, USA, 685-694.

7. Felix Kosmalla, Florian Daiber, and Antonio Krüger. 2015. ClimbSense: Automatic Climbing Route Recognition using Wrist-worn Inertia Measurement Units. In Proceedings of the 33rd Annual ACM Conference on Human Factors in Computing
Systems (CHI '15). ACM, New York, NY, USA 2033-2042.

8. T. Loukova, T., \& L. Vomacko, L. 2008. Motivation for climbing and mountaineering. 4th International Mountain and Outdoor Sports Conference. Outdoor Activities in Educational and Recreational Programmes pp. 135-139.

9. Sven Mayer, Knierim, P. Wozniak, P. and Funk, M. 2017. How Drones Can Support Backcountry Activities. Retrieved from the NatureCHI workshop: http://www. naturechi. net/papers/NatureHCI2017Mayer.pdf

10. Eleonora Mencarini, Antonella De Angeli, and Massimo Zancanaro. 2016. Emotions in climbing: a design opportunity for haptic communication.

In Proceedings of the 2016 ACM International Joint Conference on Pervasive and Ubiquitous Computing: Adjunct (UbiComp '16). ACM, New York, NY, USA, 867-871.

11. Thomas W. Merrill. 2008. Masters and Possessors of Nature, The New Atlantis, Number 19, Winter 2008, pp. 91-107.

12. Johannes Schöning, Panov, I., Kessler, C., 2007. No vertical limit - Conceptual LBS design for climbers, in: Extended Abstracts on Human Factors in Computing Systems - CHI EA'07. pp. 1- 5.

13. Mark Rouncefield, Keith Cheverst, et al. 2005. Understanding space, place and 'community', In Proc of Interact 2005 Workshop on 'Space, Place and Experience in $\mathrm{HCI}^{\prime}$. Rome, Italy. Sept. 2017.

14. Lito Tejada-Flores. 1968. Games Climbers Play. Alpine Journal. 46-52.

15. Viswanath Venkatesh and Fred Davis. 2000. A theoretical extension of the technology acceptance model: Four longitudinal field studies, Management Science, 46 (2): 186-204. 